BULLETIN Bulletin hispanique

HISPANIQUE Université Michel de Montaigne Bordeaux

116-1 | 2014

Varia

\title{
El Quevedo del Tribunal de la Justa Venganza
}

\section{Manuel Ángel Candelas Colodrón}

\section{OpenEdition}

\section{Journals}

Edición electrónica

URL: http://journals.openedition.org/bulletinhispanique/3169

DOI: 10.4000/bulletinhispanique.3169

ISSN: $1775-3821$

\section{Editor}

Presses universitaires de Bordeaux

\section{Edición impresa}

Fecha de publicación: 1 junio 2014

Paginación: 107-120

ISBN: 978-2-86781-931-5

ISSN: 0007-4640

\section{Referencia electrónica}

Manuel Ángel Candelas Colodrón, «El Quevedo del Tribunal de la Justa Venganza », Bulletin hispanique [En línea], 116-1 | 2014, Publicado el 01 junio 2017, consultado el 23 mayo 2020. URL : http:// journals.openedition.org/bulletinhispanique/3169; DOI : https://doi.org/10.4000/bulletinhispanique. 3169 


\title{
El Quevedo del Tribunal de la Justa Venganza
}

\author{
Manuel Ángel Candelas Colodrón \\ Universidade de Vigo - España
}

L'article propose de relativiser, à la lumière des genres et de la sociologie culturelle, la valeur de la polémique suscitée par la publication du Tribunal de la Justa Venganza contre les æauvres de Quevedo écrites entre 1626 et 1633.

Mots-clés : Francisco de Quevedo, Inquisition, Histoire culturelle, polémiques littéraires, Tribunal de la Justa Venganza.

El artículo pretende relativizar, a la luz de los géneros y de la sociología literaria, el valor de la polémica suscitada por la publicación del Tribunal de la Justa Venganza contra los libros de Quevedo impresos entre los años 1626-1633.

Palabras claves: Francisco de Quevedo, Inquisición, Historia cultural, Polémicas literarias, Tribunal de la Justa Venganza.

This article tries to put into perspective, under the light of the Gender Theory and Literary Sociology, the value of the controversy aroused by the publication of the Tribunal de la Justa Venganza against the books of Quevedo printed between 1626 and 1633.

Keywords: Francisco de Quevedo, Inquisition, Cultural History, Literary Controversies, Tribunal de la Justa Venganza.

$\mathrm{D}$ os aprobaciones de agosto de 1635 necesitó el autor (o autores) del Tribunal de la Justa Venganza para que su libro fuese impreso en Valencia sin cortapisas ${ }^{1}$. El padre Lanuza, de los agustinos, y el doctor Esquierdo, teólogo de la Universidad de Valencia, precedieron al doctor Pedro Dolz,

1. Cito por la reciente edición de Victoriano Roncero atribuida a Luis Pacheco de Narváez, El Tribunal de la justa venganza, Pamplona, Eunsa, 2008. Los números de las páginas se incorporan al texto. 
canónigo de Zaragoza, para que éste expidiera la oportuna licencia. En ambas se advierte que las execraciones y epítetos empleados no se pudieran excusar de no ser el asunto tan importante. "Áspero y execrativo» (p. 40) define su estilo el catedrático Esquierdo, pero tanto uno como otro celebran el rigor y la justeza de las refutaciones contra los escritos de Quevedo. Pueden ser juzgadas como poco relevantes y aun como rutinarias, pero no deja de suscitar comentario el hecho de que señalen objeciones de ese calibre.

El autor (o autores) de semejante discurso comienza su libro con una advertencia muy definida a sus lectores, al presentarlo como desagravio de los «torpes y escandalosos escritos de un autor que hoy vive entre nosotros, a quien aplauden y celebran en hiperbólicas alabanzas los poco advertidos de lo simulado que viene en ellos Satanás». A los epítetos "desdichado e infeliz», aplicados con generosidad a Quevedo, añade el autor del libelo «hijo de perdición, en precipicios de errores, con crasísima ignorancia y pérfida malicia» o directamente como «resuello de Lucifer» (p. 41). El propósito de que el lector se apiade de él o que se conduela con su inclinación infernal no es óbice para que, sin salir de ese mismo prólogo, el autor de esta diatriba contra Quevedo refiera los aspectos fundamentales de su acérrima censura. Estos aspectos son los que conforman el Quevedo que se irá construyendo a lo largo del texto $y$, que, confrontado con otros textos de igual tenor polémico contra el autor del Buscón, acaba por dibujar un prototipo probablemente satírico que, bajo el nombre de Francisco de Quevedo, se mueve en el territorio de la literatura de la época. En este punto, no interesa tanto afinar la verdad o incluso la verosimilitud de estas facetas, desde una perspectiva falsamente biografista, cuanto descubrir cómo se forja un retrato público del autor, cómo se urde un personaje que se mueve más en el papel de las polémicas que propiamente en el Madrid de 1635.

Para aclarar la cuestión sobre el Tribunal de la justa venganza conviene recordar que se trata de una invectiva contra los escritos de Quevedo, que surge alimentada por una secuencia de polémicas anteriores más o menos conocidas. Si escribo «más o menos» es porque en el relato de las desavenencias previas no todos se ponen de acuerdo. Consigno aquí las indiscutidas, a riesgo de que estas también puedan ser en algún momento puestas en duda. En el Tribunal se censuran (aparte de al propio Quevedo) la Perinola, escrita muy probablemente en 1632, el Buscón, en su versión barcelonesa de 1626, los Sueños en las versiones de 1627, el Discurso de todos los diablos, en su versión gerundense de 1628, y, de nuevo, algunos pasajes de los Sueños y del Discurso de todos los diablos, corregidos en la edición de los Juguetes de la niñez, de 1631.

La difusión de la Perinola quizá activase la redacción de esta diatriba. Pero la cuestión venía de más atrás. La publicación de Política de Dios, del Buscón, ambos en 1626, de los Sueños, en 1627 y del Discurso de todos los diablos, en 1628, motivó la presentación de una denuncia al Tribunal de la santa Inquisición, firmada por Luis Pacheco de Narváez, famoso maestro mayor de armas, escritor de tratados sobre esgrima, titulada con toda evidencia Memorial denunciando al Tribunal de la Inquisición contra cuatro libros (Politica de Dios, 
el Buscón, los Sueños, Discurso de todos los diablos) de Quevedo². Todo apunta a una redacción preparada a finales de 1629 o a comienzos de 1630. Por esas mismas fechas, o quizá un poco antes, en el verano de 1629, el fraile Diego Niseno escribió una censura al libro del Discurso de todos los diablos de 1628. Los puntos tratados en ambos escritos están trasladados al texto del Tribunal, lo que hace suponer, con escasas dudas, que ambos autores, Pacheco y Niseno, fueron también autores de la invectiva contra Quevedo ${ }^{3}$.

Los textos de Pacheco de Narváez y de Niseno debieron surtir algún efecto en el tribunal inquisitorial, ya que tanto en la versión B del Buscón (que curiosamente sirvió para fechar esta versión como más moderna) como en las de los Sueños o del Discurso de todos los diablos se advierten modificaciones que parecen atender las denuncias presentadas por ambos. La Inquisición, de hecho, mandó ejecutar la prohibición de "varias obras que se intitulan de don Francisco de Quevedo y dizen ser suyas, impressas antes del año de 1631 , hasta que por su verdadero auctor, reconocidas y corregidas, se vuelvan a imprimir.» ${ }^{4} \mathrm{Y}$ el propio texto del Tribunal (que transcribe algo más libremente esta prohibición) lo recuerda: «Y que constaba esto por el Expurgatorio que mandó hacer y salió este mismo año» (p. 138).

Por el medio, Quevedo escribe la Perinola, un vejamen contra el libro misceláneo, con pretensión de almanaque, Para todos de Pérez de Montalbán. La diatriba contaba como víctimas colaterales con los dos censores de la obra, don José de Valdivieso y, sobre todo, con Diego Niseno, a quien no debió de parecerle demasiado admisible verse mencionado, con burla e algo de sarcasmo, en el texto satírico quevediano ${ }^{5}$. Aunque, a decir verdad, la broma no estaba a la altura insidiosa del resto del libro, ya que quedaba limitada a un pequeño

2. Véase en Luis Astrana Marín, ed., Obras completas de don Francisco de Quevedo. Obras en verso. vol. II, pp. 1043-1050a.

3. María José Tobar («La huella de Diego Niseno en El Tribunal de la justa venganza», BRAE, XC, enero-junio 2010, pp. 131-157) demuestra con todo detalle que la parte correspondiente al Discurso de todos los diablos es de Diego Niseno y advierte que el texto del Tribunal amplificó la extensión del anterior y añadió numerosas citas de las sagradas escrituras y de autoridades eclesiásticas. María José Tobar, que plantea «o bien Pacheco se sirvió [...] de ese escrito ajeno sin la aquiescencia de su autor, o bien el fraile basilio participó, de forma más o menos activa, en la elaboración del libelo» (p. 145), sostiene como conclusión que Diego Niseno tuvo un papel directo en la redacción del Tribunal.

4. Antonio Zapata, Novus Index librorum prohibitorum et expurgatorum, Sevilla, 1632. f. 399.

5. Fernando Plata, a propósito de uno de los códices de la Biblioteca Nacional que contiene uno de los manuscritos de La Perinola, describe un opúsculo, que atribuye a Diego Niseno, titulado Censura del libro que compuso Juan Pérez de Montalbán intitulado "Para todos" y respuesta a «La Perinola» que contra él escribió con este título Don Francisco de Quevedo Villegas. En él advierte que estas tres notas de la burla quevediana aparecen recogidas y comentadas por este Niseno, que se autorretrata, al defender con elogios en tercera persona al Reverendo Padre Maestro fray Diego Niseno, con «personalidad megalómana» en palabras del propio Fernando Plata. Interesa añadir a esta pequeña polémica, pues, esta Censura, como paso previo al Tribunal de la justa venganza (Fernando Plata, "La polémica en torno a La Perinola de Quevedo con un texto inédito», La Perinola 10, 2006, pp. 245-255). 
juego de palabras sobre Niseno («Ni sé, ni no») y a un excesivo regodeo sobre la ignorancia del religioso a costa de un ligero error:

No toco en la aprobación del Padre Niseno, que ese está lastimado de que el Autor le saque el soneto de la celda a pública plaza, que a persona que escribe puntos predicables sacarle sonetos en libro de bataola es burla pesada: sólo advierto que su Patenidad ha hecho poner todos los Autores que escribieron antigüedades y varias lecciones y porque para poner 23 cabales, viendo que le faltaba uno, hizo de uno dos, citando con sus comas en medio, Ficino, y Marsilio, y ello de verdad, fue un mismo Autor que se llamó Marsilio Ficino.

A estas críticas podría añadirse la acusación de corresponsabilidad achacada por Quevedo a estos dos hombres en algunas observaciones de apariencia más severa: el comentario de Quevedo sobre el parangón que establece Montalbán entre Cristo y Ulises que Quevedo ve impropio y hasta blasfemo debió de herir la sensibilidad del fraile Niseno, quien lo recuerda en el Tribunal con especial insistencia:

Pues aunque vuestras mercedes no son Niseno, ni Valdivieso, miren si aprobaran el decir el Doctor de su propia escritura hablando de Cristo, a quien hace Ulises, dijo con cautela: yo soy. (...) Esta es calumnia de los escribas y fariseos a quien respondió Cristo: Ego palam locutus sum (Yo he hablado en público), y en otra parte: Ego sum via, veritas et vita (Yo soy camino, verdad y vida). Y también es proposición de los cristimástiges, en el libro blasfemo que intitularon De tribus impostoribus mundi, que acabó quemado con sus autores en Alemania. Pues ¿cómo se ha de defender decir que Cristo habló con cautela, y pasar con dos aprobaciones, y la postrera de un teólogo y provincial tan grave?

Esta insinuación de herejía debió de molestar a los autores del texto del Tribunal, lo que explica que, a pesar de que ya eran conocidas las denuncias de las obras quevedianas, decidieran presentarlas bajo capa de nuevo texto y de nuevo formato. La fecha de 1635 (agosto) de publicación del Tribunalse antoja, no obstante, bastante alejada de la redacción de estos dos textos primarios, por lo que se puede conjeturar que la propia composición del Tribunal o debió de prolongarse en el tiempo (casi desde 1629) o, lo que parece más probable, debió de emprenderse (o reemprenderse) tras la salida a la luz de los Juguetes y aun más con el texto de la Perinola en 1632 (o 1633). Aun en este caso, parece lapsus grande desde 1632 hasta 1635 el de la redacción de esta diatriba enjundiosa, sobre todo si se tiene en cuenta la irritación que pudo haberle causado a Diego Niseno, en especial, los comentarios de Quevedo sobre las aprobaciones del Para todos en su diatriba y, todo ello, sin contar las cínicas observaciones, en un contexto plenamente satírico, con las que denuncia la mezcla en el libro heterogéneo de Montalbán de lo profano y lo religioso. Tales comentarios que podemos entender maliciosos (si se interpretan como respuesta indirecta a las conocidas censuras de Pacheco y Niseno) resuenan respondidos a cada paso de la invectiva del Tribunal.

Presentada esta pequeña historia de la diatriba, intento ver la dimensión pragmática de este texto que tantas veces aparece en la biografía de Quevedo, 
escrita y fabricada a lo largo del tiempo. Procuro analizar qué Quevedo aparece ahí y cuál es la finalidad de trazar este perfil en apariencia plano en su perversidad y maldad sumas. Tengo que admitir que mi punto de partida venía seriamente predeterminado, algo condicionado o muy condicionado, por la tópica sobre el texto antiquevediano, de un modo semejante al que tenemos con otros textos quevedianos que a la inversa aparecen resueltos con un par de aseveraciones contundentes. No voy a entrar a enjuiciar la inevitable determinación previa que la construcción de ciertos clichés de algunos textos posee, pero los epítetos «inmundo libelo», "virulentos o serios ataques», que he ido recogiendo desde las ediciones más antiguas, y aun recientes, sobre el Tribunal impedían una apreciación ecuánime de los textos en cuestión. No sé hasta qué punto la coincidencia en la adjetivación retraía mi adhesión a tales tesis, ya que parecía colocarse ahí de forma casi automática a propósito, a modo de filtro (u ocultamiento, según se mire) del texto que me traía entre manos. Sería interesante comprobar cómo la inclusión de ese adjetivo al parecer inocente, a veces casi redundante, en combinaciones con sátira, libelo u opúsculo no logra al cabo diseñar una construcción deliberada de una historia. Conviene desmontar algunas piezas.

Lo primero que llama la atención es el seudónimo/anónimo del texto. A pesar de las licencias, el texto salía bajo la rúbrica de un autor inventado: Arnaldo Franco-Furt. Pocos candiles hacían falta para alumbrar la autoría del texto y, sin embargo, disfrazan su nombre ${ }^{6}$. El autor propone una narración satírica, al modo del vejamen académico ${ }^{7}$. En ella, un correo llega de noche a Sevilla y aprovecha que está abierta una mancebía para vender y anunciar en ella el libro de La Perinola quevediana. El modelo es exactamente el mismo que emplea el propio Quevedo en su vituperio contra el Para todos de Montalbán. Una concurrencia de distintos personajes pone en discusión pasajes del libro: mientras en la Perinola se trata de zaherir, sin ahorro de burla, las distintas partes del heterogéneo volumen de Montalbán, en este Tribunal, los personajes, algo más elevados, intentan denunciar, de forma más solemne y bajo la fórmula

6. Parece signo de la propia polémica: Fernando Plata («La polémica en torno...», art. cit., p. 248) sugiere que los primeros manuscritos de La Perinola debieron de correr en los meses de la primavera de 1632 de forma anónima.

7. Victoriano Roncero, en su edición ya citada del Tribunal, en la que demuestra que Pacheco de Narváez escribió el discurso, considera una prueba «irrefutable» de esa autoría «la carta de un desconocido, escrita en 1635, en la que se relatan acontecimientos ocurridos entre el 18 y 25 de octubre de ese año y donde se afirma : «Don Luis de Narváez está preso muy estrecha y apretadamente por haber compuesto y dado a la estampa una comedia en prosa, que es una sátira muy atroz y continuo sarcasmo contra don Francisco de Quevedo, y, aunque pudiera muy bien don Luis haber excusado esta pesadumbre, porque se ofrecían otros a quien poder atribuir y achacar este escrito, no quiso, porfiando que él era su autor y no otro ninguno, enamorado de su obra, al modo de un padre que quiere y estima a su hijo» (p. 19). Por la fecha de la carta y la referencia a Pacheco de Narváez - concluye Roncero- queda claro que la "comedia en prosa» a que se refiere el autor de esta misiva no puede ser otra que el Tribunal.» De ser cierta esta conclusión de Roncero, habría que entender, pues, el texto del Tribunal más como una sátira o una comedia que propiamente como un libelo polémico con intención penalizadora. 
judicial, los excesos de los libros de Quevedo, incluso con la presencia (a veces casi testimonial) de un abogado de la defensa. El autor de este libelo contra Quevedo recuerda en la crítica de la Perinola que el libro quevediano es vejamen («cosa tan permitida y usada en las universidades», p. 45) y es indudable que cerca de este subgénero (tan celebrado y cultivado en el siglo XVII) se encuentra este texto ${ }^{8}$.

Esta caracterización genérica es el segundo de los aspectos destacados: la condición de vejamen (con ese marco narrativo que pronto por la elección del modelo forense se convierte en modo drammatico) puede explicar el contenido del texto. A los lectores atentos de este discurso (incluso a nuestros contemporáneos) les puede sorprender la prolongada acusación, la parcialísima vehemencia con que se trata tanto la figura como las obras y los escritos de Quevedo. Pero, desde el punto de vista del subgénero, esta vituperatio es lo esperable. El posible autor del libelo, Pacheco de Nárvaez, por lo que se dirá, escribió por esa misma época otro texto semejante, que al parecer no tuvo esa repercusión pública (y en este caso, con nombres y apellidos) y que mantiene con éste una relación notable. Me refiero a los Peregrinos discursos y tardes bien empleadas (1639), en el que cinco peregrinos (entre ellos un teólogo) que vuelven de Santiago acometen la tarea de enjuiciar la Política de Dios quevediana?.

¿Qué es lo que se denuncia en este Tribunal de la obra de Quevedo? En un pasaje extenso, pero significativo por su capacidad de síntesis, el autor del libelo desgrana, con un orden muy definido, el que va desde lo más sublime a lo más bajo, los errores y las maldades quevedianas. Son quince: resumidas, permiten hacerse cargo de la imagen pretendida (construida) del sujeto que se procura reprobar. El orden retórico con criterios de jerarquía teológica, desde las esferas más elevadas hasta los asuntos más domésticos, explica la relación:

1. Sus temerarias y sacrílegas proposiciones en que adultera y contradice el Sagrado Texto.

2. El desprecio que con máscaras de donaires hace de las cosas que la católica Iglesia tiene dedicadas al divino culto.

3. La irreverencia con que trata las beatísimas efigies.

4. El injurioso y diabólico rencor con que habla de aquellos que para el más venerable y misterioso Sacamento se les da y tienen tan suprema potestad.

5. La radical indignación con que agravia a las que (...) consagran su virginidad y se sacrifican a eterna clausura.

6. La injusta y maliciosa sospecha que pone en los eclesiásticos jueces.

7. El descrédito con que con insolentes palabras pone a los que nos gobiernan.

8. Las calumnias y afrentas que supone y les dice a los que (...) sirven a la república.

9. El deshonesto gozo con que habla y aprobación que hace de los deshonestos y lascivos deleites.

8. En el prólogo al lector del Tribunal el autor insiste en varias ocasiones en que la materia del texto no se aleja demasiado de la empleada por el propio Quevedo para sus censuras: «imitando a su autor en negar aquello mismo que desea y procura que se sepa, aunque negando el ser suyo, que semejantes materias siempre las escribió asasinamente».

9. Luis Pacheco de Narváez, Peregrinos discursos y tardes bien empleadas, ed. Aurelio Valladares Reguero, Pamplona, Eunsa, 1999. Su editor, Aurelio Valladares, que descubrió y estudió el manuscrito de este texto, advierte similitudes con el Tribunal, en especial, la disposición que el propio Valladares denomina dialogística para librar la diatriba. 
10. Lo que califica y alaba el distraimiento y vida holgazana de los bribones y estafadores.

11. La perversa instrucción con que enseña a hurtar y que los hurtos se encubran con lo sagrado y más temido de los demonios.

12. La inicua inhumanidad con que a todas las almas condena a las penas infernales.

13. El conato con que solicita que estas penas se desprecien y no se teman.

14. El atribuirle a Lucifer imperio y soberanía, con supremo tribunal.

15. [Y sobre todo] El insolente atrevimiento con que pretende inquirir los juicios y secretos que el Altísimo Señor reservó en sí mismo y enmendar las obras que hizo con su eterna sabiduría. (pp. 41-42)

Sobre las consideraciones de esta naturaleza se describe el característico defecto de la cojera, pata coja, diablo cojuelo, derrengado, los episodios bajo el gobierno de Osuna (que podrían dar alguna pista sobre el particular: robar en Nápoles y Venecia, y ser ingrato al propio duque por negarlo y no defenderlo ante las acusaciones de cohecho y corrupción), y derivado de ello, su injusta pretensión del señorío de Juan Abad, la compra del hábito de la orden de Santiago (o en su defecto por intercesión de los duques de Uceda o de Osuna) o la condición de miles gloriosus por ser «un pobre capigorrón y mísero porcionista» (p. 47). Algunas de estas viñetas aparecen en los textos de denuncia anteriores, pero aquí se hacen reiteradas. Da la impresión de que la imagen del poeta adquiere rasgos de plena sátira reducibles, casi por convención, a una expresión caricaturesca, a apenas tres rasgos caracterizadores, suficientes para armar la etopeya de un ser con defectos a un tiempo morales.

Tal simplificación, tal reducción de la imagen a pequeñas líneas execrables, no va más allá de una mera indicación satírica. Ese retrato quevedesco sólo puede dirigirse a quien distingue en tales rasgos la figura preconcebida del autor. Estamos más bien ante un Quevedo prefigurado que ante un personaje que se va creando a lo largo de esta pintura de invectiva. En muchas de las resoluciones del juicio al que se ve sometido Quevedo, los miembros de este tribunal se encuentran con dilemas sobre el castigo elegido o sobre la competencia jurídica del mismo. Tienden en ocasiones a dejar pasar la acusación por hallarla escasa de valor o porque consideran que deben trasladar la sustancia de la denuncia a una instancia superior. Siendo religioso el denunciante, en ocasiones deriva su decisión a otros lugares: esta ambigüedad llama la atención en un texto generalmente pensado para llevar al acusado a los castigos más elevados. Así como llama aún más la atención la ligereza con la que asumen su resolución final. También es fácilmente comprobable cómo a medida que va avanzando el texto de la diatriba las conclusiones sobre el mismo van menguando hasta el punto de que, al final de la invectiva con los textos de Juguetes de la niñez hay más paráfrasis, casi resúmenes, del texto quevediano -leemos textos enteros de la obra quevediana sin apenas comentarios- que propiamente una labor reprensiva. En el extremo de este procedimiento se hallan pasajes incluso en los que la severidad (y con ella la finalidad rigurosa de la reconvención) queda en entredicho, en especial al comienzo, con ligero tono escolar, como cuando hace mención a lo «sucio del lenguaje» quevediano con el acopio de expresiones 
"chabacanas, groseras y torpes» ${ }^{10}$. Uno de ellos parece impropio: es aquel en el que se censura el pasaje del Buscón de la mitra y los tres mil cabos: la sentencia concluye con la ley del Talión: «mandaran ejecutarlo irremisiblemente, para que viese si le estaba bien la mitra que dice y avisase si le sabían bien los nabos» (p. 82). O esa secuencia de castigos (algunos de una singularidad algo extravagante) que van sugiriendo una progresión:

1. Esté don Francisco de Quevedo recluso en un convento, hasta que bien catequizado en los sacramentos que instituyó Cristo Señor nuestro, sepa que el tercero fue el de la penitencia y asimismo decore en la cartilla de los niños los mandamientos de nuestra madre la Iglesia (p. 62).

2. Que en el convento donde don Francisco de Quevedo estuviere recluso salga delante de su comunidad descubierto y sin cinto, con una mordaza en la lengua y que el prelado, después de una rigurosa fraterna, le manifieste cómo en la tierra es tan grande la dignidad de sacerdote (p. 63).

3. Dijeron que por los dos primeros cargos en el convento donde tuviese la reclusión, lo sacasen al refectorio los tres primeros viernes, desnudo de la cintura arriba, y en cada uno de ellos se le diese una disciplina de rueda desde el prelado hasta el novicio. Y después, estando tendido en la puerta, pasasen por encima dél todos los religiosos sacerdotes diciendo lo del psalmo 92.: super aspidem, et basiliscum ambulabis, et conculcabis leonem et draconem. Y que los novicios y legos, poniéndole los pies en la boca, dijesen aquel verso del psal. 57: «Dios quebrantará los dientes de los pecadores, y las muelas de los leones quebrantará el Señor». Y que por el desacato de que el cura y los estudiantes se ensartaron en un asno, lo llevasen a la huerta del dicho convento y fuese puesto para traer la noria, por diez horas, con un bozal de esparto en la boca, y que un donado, dándole latigazos, le hiciese andar muy aprisa y que en caso que no hubiese noria, se conmutaba en atahona, y que se le diese de ración otro tanto como había de comer el mulo o jumento a quien como a su igual sostituyese (p. 66).

No deja de tener un cierto grado de sarcasmo la proporción buscada, lo que a mi juicio acerca esta diatriba de forma más que evidente al modelo satírico del que se confiesa, aunque tímidamente, deudora, y no como un mero ataque virulento, que parece conceder importancia sustancial a la censura. No deja de ser significativo, por muy hagiógrafo que presumamos a Pablo de Tarsia en su pretensión de cuajar una imagen beatífica y honorable de Quevedo, que recuerde, en el año algo ya lejano a los hechos, de 1663, que Quevedo hizo caso omiso a estas intervenciones críticas:

A otros Quevedo mastiges pudiera nombrar, pero dejólos sentenciados a muerte por su mismo tribunal, que tomó justa venganza de los acusadores, sin que para la sentencia y ejecución de ellas precediera jamás diligencia del inocente condenado, dejando el suceso al escrutinio de la verdad, juez despasionado y a la defensa del tiempo, abogado muy elocuente, que sin trampa legal, descubre la falsedad de los procesos, formados con pasión y envidia. Con estos valedores estuvo tan ajeno don Franciso de volver por sí que, habiendo visto el Almirante de Castilla, Príncipe laureado de victorias, y otros Señores de la Corte, sus amigos, el libro del Tribunal, pertrechado con osadía y atrevimiento, y, persuadiendo todos a don Francisco le diese el asalto con el cañón de

10. Especialmente curiosa es la relación de palabras que, según el detractor, vulneran el estilo de una posible confutación: «azúcar, moscas, palos, pelos, pajas, tejado, vidrio, cascos de olla, calzas viejas, urraca, laguna, ortigas, romero, adelfa, tronchos, achicorias y otras inmundicias que por asquerosas no se refieren» (pp. 48-49). 
su pluma, se excusó de la empresa, diciendo: «Eso fuera, señores, ser tan ruin yo como los que le escribieron; seguiré al sabio que me aconseja no responder al loco según su locura, Proverb. Cap. 26. Vers. 4. Ne respondeas stulto iuxta stultitiam suam, ne efficiaris es similis». ${ }^{11}$

Eliminada la parte correspondiente al ánimo encomiástico del biógrafo, la anécdota puede indicar en el fondo que Quevedo poco vio de enjundia en ese texto: tal vez la consideró amplificación, algo reiterativa y trufada de erudición à la page, de dos textos esenciales que él ya conocía rubricados con sus nombres y con sus apellidos: el Memorial de Luis Pacheco de Narváez entregado a la Inquisición y la Censura también enviada a la Inquisición por el fraile Basilio Diego Niseno.

Tanto la Perinola como todos estos textos forman parte de una especie de permanente disputa del campo literario: un modo de combate por la hegemonía política del espacio erudito e incluso doctrinal. La lucha, en este caso, puede poseer mucho de ceremonial, de trivialización de la mera polémica. No pretendo rebajar el sentido zahiriente de todo vituperio público, con pretensión además de que actúe la justicia religiosa en este caso, pero, leído con especial cuidado, no aporta grandes novedades al estado de cosas anteriores. Quevedo lleva desde mucho antes au cour de la mêlée, al tanto de cada disputa o polémica. Escribe el Memorial por el patronato de Santiago con el respaldo de la Orden de Santiago y (con encargo) del cabildo compostelano en 1628 (de esta fecha cabría comenzar la tormentosa relación con Olivares); escribe $S u$ espada por Santiago casi motu proprio ese mismo año con propósito beligerante, bajo la fórmula precisamente de la refutación de otros textos participantes en la polémica jacobea; se la pasa, como sabemos, en forma manuscrita, al secretario del conde-duque para que éste la pueda leer, pero el mismo secretario con prudencia y prevención se la devuelve con el consejo/ advertencia de que no es oportuno enviarla. Escribe a finales de 1629 El chitón de las tarabillas con idéntica traza polémica y semejante ambigüedad belicosa; y en 1633 escribe la Execración contra judios aunque la oculta. La Perinola no deja de ser en este recorrido un jalón más de un fenómeno a mi juicio más común de lo que pensamos. El número de textos, libelos, papeles, memoriales que cualquier asunto llegaba a promover en esa época (en un torbellino muchas veces de respuestas) es ingente, y prueba que este ejercicio dialéctico comenzaba a ser en muchos casos un fin en sí mismo: un modo particular de distinción individual, una manera de ocupar un lugar en el campo literario antes que una aplicación pragmática de su posición política.

En un trabajo sobre la autorrepresentación de los autores del siglo XVII (con Lope, Cervantes, Góngora y Quevedo como paradigmas), Carlos M. Gutiérrez recuerda las palabras de Ettinghausen sobre una especie de cambio de estrategia en Quevedo a partir del índice inquisitorial: «La publicación en 1635 del

11. Pablo de Tarsia, Vida de Quevedo, facsímil de la edición princeps de 1663, Aranjuez, Ara Iovis, 1988, pp. 52-53. Hago notar la expresión mastiges, que es la que Quevedo, en cita ya referida, emplea (cristimastiges) en La Perinola contra el doctor Montalbán. 
Retraido de Jáuregui y del Tribunal de la justa venganza, así como las denuncias de sus escritos (...), también debieron de influir en esa decisión de cambiar su imagen literaria de autor mordaz y hasta tirando a herético por la de moralista devoto y erudito». ${ }^{12}$ Se habla, pues, de imagen literaria (mordaz y herético) y, en ese contexto, la exégesis burlesca de otros textos como hallamos en Para todos o el vejamen directamente estaban a la orden del día. La crítica moderna tiende, a mi juicio, a solemnizar o a otorgar trascendencia biográfica a un fenómeno que tal vez pudo carecer de ella. O, en el otro extremo, a negar o evitar en lo posible su mención por considerar que tales ejercicios son defectos de intelectuales iracundos o de literatos que pierden el tiempo en batallas inútiles. Los adjetivos inmundos, nauseabundos o infamantes (traidos de textos críticos) definen la naturaleza de los términos del Tribunal, probablemente esperables y necesarios en un discurso de estas características. En algunos trabajos contemporáneos se insiste en la gravedad de estos textos, en el impacto personal que causan en los individuos la salida a la luz de tales discursos, pero creo que convendría relativizar la importancia que adquiere la disputa política y literaria al respecto. Fernando Bouza dejó escrito, con humor creo, que la historia cultural del siglo de oro se caracteriza "por una alta tasa de litigiosidad ${ }^{13}$ : «rebosa de saña escrita, contra esto y aquello, por casi nada y para casi todos». ${ }^{14}$ Sin duda alguna, tal animosidad injuriante debía de resultar al cabo rutinaria, de tal modo que lo que hoy consideramos violentos ataques de consecuencias casi inevitables pueden perfectamente asimilarse, integrarse, casi neutralizarse en este maremagnum de diatribas constantes. Quevedo, es cierto, modificó en muchos pasajes (acuciado por la prohibición) algunas de las indicaciones que figuran en el texto del Memorial de Pacheco a propósito de los Sueños o del Discurso de todos los diablos (o sobre el Buscón, aunque este de modo más secreto). Pero el texto del Tribunal era redundante en la mayor parte de los casos. Tal vez, por lo que señala el propio Menéndez Pelayo al comprobar, como hemos visto, que los autores de las censuras no estaban del todo satisfechos por el alcance de las medidas adoptadas contra Quevedo y parecían pedir más. Los lamentos incluidos en la última parte del Tribunal ejemplifican que las acusaciones primeras no tuvieron el impacto deseado. Item más: las acusaciones, en estos casos, van más dirigidas a los que permitieron la publicación de los Juguetes de la niñez que al propio Quevedo: apuntan a su responsabilidad a la hora de la censura.

Leido con este sentido, el texto del Tribunal de la justa venganza es lluvia que cae sobre suelo demasiado mojado. Un epitafio como el que contiene el texto

12. Carlos M. Gutiérrez, «Narrador, autor y personaje. Facetas de la autorrepresentación en Góngora, Lope, Quevedo y Cervantes», Espéculo (junio 2005-febrero 2006). Se refiere en su artículo al trabajo de Henry Ettinghausen, "Quevedo, ¿̨un caso de doble personalidad?», en Homenaje a Quevedo, Academia Literaria Renacentista II, Salamanca, Universidad de Salamanca, 1982, reimpreso en 1996.

13. Fernando Bouza, Papeles y opinión. Politicas de publicación en el siglo de oro, Madrid, CSIC, 2008, p. 99, nota 15.

14. Fernando Bouza, Corre manuscrito. Una historia cultural del siglo de oro, Madrid, Marcial Pons, 2001, p. 109. 
(al final de la tercera audiencia, que bien pudo haber sido el final provisorio del discurso, pero que las circunstancias mudó en este texto que creo un work in progress) puede parecernos terrible $\mathrm{y}$, en efecto, así les parece a quienes lo comentan, pero no es más (ni menos) que una repetitiva salmodia de insultos sin tasa:

Aquí yace don Francisco de Quevedo, mal poeta y peor prosista, lisonjero temporal, bufonador perpetuo, simbolo de la ingratitud y de la iniquidad, vano presumidor de ciencias (ignorándolas todas) graduado en torpes y deshonestos vicios, catedrático de la sensualidad, cuya mordaz y satírica lengua dijo y escribió mal de todo y de todos sin exceptuar lo divino ni lo humano. ¡Oh tú que miras su infame sepulcro, huye dél y ruégale a Dios que le dé el castigo que merecen sus palabras, obras y escritos (p. 106).

Pero no estoy tan seguro de que a Quevedo le pudiera haber hecho el mínimo daño o rasguño, ya que la mayor parte de las acusaciones ya habían sido hechas y, lo que es más importante, atendidas en mayor o menor sentido. Quevedo debió de juzgar insistentes a los autores del escrito, pero no menos insidiosos que antes y sus razones, por ello, impertinentes. Los argumentos se ampliaban con acarreo erudito, a la manera tópica de las batallas dialécticas (hinchadas de referencias reiterativas), y se amplificaban, con escasa novedad, las invectivas anteriores. Las censuras de la Perinola explican la composición del libro, como un vejamen más en la línea de tantos, y las críticas a los Juguetes de la niñez se exponen más para reconvención de los laxos censores del libro que para el redoble de la crítica quevediana. Abunda en este parecer la perplejidad que le causa a Aurelio Valladares Reguero, estudioso de la obra de Pacheco, el hecho de que el maestro esgrimista, severo en las denuncias, nunca entrara «en el mismo campo de batalla de su contrincante, salvo si admitimos la paternidad de El Tribunal de la justa venganza, que por su atrevimiento resulta más quevedesco $»^{15}$.

La particular condición del libro como vejamen, la repetición de los argumentos ya sabidos por casi todo el mundo (especialmente por el propio Quevedo, que no vio nada nuevo que antes no supiera), la irritación sobrevenida por los autores del libelo por comprobar que los textos de Juguetes conservaban, según su criterio, buena parte de sus características principales (con el beneplácito de dos censores que avalaban doctrinalmente el texto) $y$, si cabe, la progresiva disminución de los ataques (con el inversamente proporcional aumento de meras copias de pasajes sin apenas comentario recriminador) a medida que se va avanzando convierten el texto del Tribunal en uno más de la trifulca permanente que Quevedo sostiene con buena parte de la clase política y literaria de la época ${ }^{16}$. Y no porque Quevedo sea, como

15. Aurelio Valladares Reguero, «La sátira quevedesca contra Luis Pacheco de Narváez», EPOS, XVII, 2001, p. 193.

16. En un trabajo muy interesante, planteado desde una óptica jurídica, José Calvo González señala las características del Tribunal como proceso penal y, tras advertir los errores procesales, concluye que «esta manera mudada y desfigurada de remedar la culminación del iter procedimental quizá supondría el uso licencia tolerable tratándose del fingimiento literario 
él mismo afirma, «de natural acreditado y belicoso» ${ }^{17}$, sino porque el campo literario de aquel momento histórico era propicio para esta clase de debates, en los que el arbitrio que supone la censura eclesiástica o la licencia para la imprenta venía determinado a expensas de esa lucha ideológica por ganar el espacio de la ortodoxia o de la fama. Una amistad, una relación favorables podían perfectamente inclinar la suerte.

En el prólogo a la edición modernizada del Para todos, tesis doctoral leida en 2005 en la Universidad de Texas, Valérie Y'llise Job recuerda la pregunta que George Bacon, en su biografía de Pérez de Montalbán (1912) formulaba sobre la Perinola: "is the Perinola an answer to some attack upon its author in the former work or is it inspired solely by malice?n, respondida con la conclusión de que "Para todos contains nothing to incite Quevedo's fury. ${ }^{18} \mathrm{El}$ reproche del autor de la Perinola contra Pérez de Montalbán por olvidar en el elenco de obras de Quevedo los libros de La polilla de las repúblicas y la Historia del año de 31 da la clave del tenor, entre divertido e intranscendente, con que emprendió Quevedo la burla del Para todos de Montalbán. No debe olvidarse que Montalbán citó en términos muy elogiosos a Quevedo (con un relatorio además de sus obras) y que no dio aparente motivo para el escarnio público:

[Francisco de la Torre] que ilustró y sacó a luz el doctísimo don Francisco de Quevedo y Villegas, ingenio tan universal en las letras humanas y divinas que en todas luce y en cada una es maestro. f. 148.

90. Don Francisco Gómez de Quevedo Villegas, caballero del Hábito de Santiago. La Defensa del Patronato de Santiago, el Epitome de santo Tomás de Villanueva, el Conocimiento de las cosas propias, la Política de Dios, impresa por Pedro Tazo en Madrid y los Sueños también impresos en Madrid y tiene para sacar a luz historia de la Providencia de Dios; Paráfrasis en verso, sobre el primer alfabeto de los Trenos de Jeremías; otra sobre los Cantares; Anacreonte y Phocilides, traducción en verso; Historia grande de santo Tomás de Villanueva, Prevención para la muerte; las Musas, Obras varias de donaire,

de un tribunal de justicia, de una ficción judicial. No obstante, toda ficción, y ésta también, contiene siempre una promesa de sentido, que aquí se revela en un particular y bien distinguible propósito; el designio en no sólo poner sino también mantener al imputado en tela de juicio. El efecto no es otro, ciertamente, que procurar una sanción reforzada, redoblada a padecida con la mera incoación del trámite de averiguación, de la pena de banquillo. Una condena a la pena de banquillo impuesta a un imputado cuya conducta difícilmente podía ser merecedora de reproche penal, añadida sobre la bastarda conminación penal ya producida con la acusación falsa, y prolongada en la que conlleva, por sí sola, el anuncio del dese cuenta a la Superioridad para la apertura de juicio oral». ("Quevedo en tela de juicio o sea el Tribunal de la justa vengança de Luis Pacheco de Narváez (De contiendas literarias y derecho en la España del siglo XVII»), en Patricio-Ignacio Carvajal-Massimo Miglietta (eds), Estudios jurídicos en Homenaje al Profesor Alejandro Guzmán Brito, Edizioni dell'Orso, Alessandria (Italia), 2011, T. I, pp. 525-544; también en ISLL Papers, Italian Society for Law and Literature, junio 2009. En cierto modo, desde esta perspectiva, el texto del Tribunal coincide con mi tesis de que parece más perseverante censura que propiamente una decidida fórmula de ataque.

17. Así escribe Quevedo al conde-duque de Olivares en la dedicatoria de Su espada por Santiago.

18. Valérie Y'llise Job, A modernized edition of Joseph Perez de Montalban's Para todos, Texas University, 2005, p. 26. 
en verso, Sonetos Morales y traducciones de latinos y griegos; Themanites, rediuivus en Job; Homer. Achill. advers. impost. Maronianas; Origen de todas las heregias y fisonomía, para conocer los Novatores que previenen persecución contra la Iglesia; que en todo son diez y ocho libros, ocasión grande para poder decir mucho del ingenio y letras de su autor, si con haberle nombrado no lo hubiera dicho todo. f. 344r-345.

Don Francisco de Quevedo las [comedias] acierta, como si las escribiera continuamente; tal es su ingenio de universal, de florido y de soberano. f. $358 .{ }^{19}$

Este desconcierto ofrece dos salidas: o se ignoran las razones que movieron a Quevedo para escribir la Perinola, lo que nos obliga a reforzar la búsqueda (no sé si fructífera o útil) de antiguas querellas, duelos no cobrados, para explicar la reacción (o acción quevediana) ${ }^{20}$, o bien se relativiza la importancia que una situación semejante puede tener en el contexto literario de la época. Esta última opción parte con indudables desventajas, si se consideran las consecuencias de tales polémicas. Pero estas no dejan de formar parte del mismo relativismo literario. La propia Valérie Y'llise Job observa con agudeza que, sin pretenderlo, la diatriba con Quevedo acabó por hundir la fama de Montalbán, no tanto por la posición que ocupaba en aquel momento (defendible en las instituciones literarias de la época) como por la secuela indirecta que el entronamiento quevediano supuso para aquellos que en vida se atrevieron a la pugna literaria o intelectual. Los "Montalván's contemporaries were influenced by Quevedo's critiques, whether justified or not, and the impact has transcended centuries to affect modern Montalván scholarship»" ${ }^{21}$.

La crítica a lo largo del tiempo ha ido canonizando la obra quevediana (incluso la más satírica) sin asomo de censura, salvo para los casos de las invectivas, siempre consideradas bajo sospecha. Cuando la diatriba es contra Quevedo, el resorte canonizador también actúa en sentido contrario provocando la denigración de su reprensor. Es difícil escapar a este designio. Sólo la recatada opinión de quienes no gustan de estos subgéneros literarios (capitales para entender la historia cultural y de la mentalidad de su tiempo) evita el escarnio público. Este comportamiento crítico se advierte incluso en épocas modernas, lo que revela una clara jerarquía en los intereses del estudio. Entramos así en una paradoja: la de asegurar que tales muestras dialécticas son insulsas pérdidas de tiempo que no merecen atención y la de afirmar que tales refriegas contribuyeron decididamente a una especie de conversión literaria del poeta, en busca de una legitimación por vía de una rectificación moral y política de sus inquietudes literarias. Tal contradicción es superable con la visión para ambos extremos de un Quevedo fetén y de otro algo menos apreciable. En este punto, creo conveniente mirar, pues, los textos de Quevedo con menos trascendencia, con menos solemnidad literaria. Con más descargo

19. José Pérez de Montalbán, Para todos exemplos morales humanos y divinos, Madrid, Alonso Pérez, 1632. Los números de las páginas se refieren a esta edición.

20. Las notas que acumula Aurelio Valladares para explicar la animadversión entre ambos, como él mismo declara, son escasamente convincentes.

21. Valérie Y'llise Job, A modernized edition of Joseph Perez de Montalban's Para todos, ob. cit., p. 50. 
para la cotidianeidad del fenómeno de la polémica y por la ubicación de su obra en el límite de la discusión ideológica. Y, en el caso de Quevedo, acostumbrado a la pelea constante, a la construcción de discursos plenamente dialécticos, subordinados al debate y a la refutación, la importancia de tales textos resulta capital, pero no menor de otros textos en los que funda su pensamiento y su forma de comprender la literatura en sentido más amplio que la pura poesis.

Esta forma de ver la proyección pública de Quevedo, ya camino de 1639 y de san Marcos de León, obliga a repensar las alianzas y las relaciones de Quevedo con su contexto. Su familiaridad con el litigio (no siempre achacable a su carácter) debe ser contextualizada en un ambiente propicio para el combate dialéctico. Desde este punto de vista, intervenir en cuanto foro exista, convenga o no convenga, le afecte o no le afecte, debe ser visto casi como una obligación de literato: en Su espada por Santiago, por ejemplo, Quevedo recuerda de su contrincante las palabras que este había escrito en defensa de las universidades de Salamanca y Alcalá y en contra de la creación de la universidad de los jesuitas, una polémica que apenas duró un año, pero de la que estaba perfectamente al tanto, como demuestran las anotaciones que figuran en los márgenes del libro que le sirvió de argumentación ${ }^{22}$. Este Tribunal puede servir también para reconocer las estrategias discursivas de la refutación o la constitución procesal de un litigio: la utilización de un texto base para el comentario crítico, fundamento de las técnicas de estudio más conocidas y, por otra parte, reiterado banco de pruebas en casi todas las obras polémicas quevedianas, subordinadas siempre al texto del que parten. Tampoco debe desdeñarse, en este punto, la concepción de la aprobación o de la censura como un género literario en sí mismo, a medio camino entre la exégesis erudita y la diatriba satírica. De tal determinación genérica se deduce una mayor relativización del impacto biográfico o biografista de esta clase de textos. Hay otros puntos para reconocer al Quevedo que puede quedar retratado en esta invectiva: un retrato más próximo a una idea mental de un Quevedo prefigurado que incluso de un retrato nuevo. Como si el escritor o escritores del Tribunal hicieran retrato del retrato, copia caricaturizada de una propia caricatura dada. Con ese propósito pleonástico, Quevedo podía estar muy tranquilo y preocuparse a finales de ese 1635 de entregarle las salchichas que acababa de hacer al duque de Medinaceli.

22. Véase Manuel Ángel Candelas Colodrón, «Quevedo contra Balboa: un 'contraste de diamante' (nota a Su espada por Santiago)», Revista de Erudición y crítica, 1, 2006, pp. 83-90 